\title{
Does Combined Anterior-Posterior Approach Improve Outcomes Compared with Posterior- only Approach in Traumatic Thoracolumbar Burst Fractures?: A Systematic Review
}

\author{
Terence Tan ${ }^{1,2}$, Tom J. Donohoe ${ }^{1,3}$, Milly Shu-Jing Huang ${ }^{1,2}$, Joost Rutges ${ }^{4}$, \\ Travis Marion ${ }^{5}$, Joseph Mathew ${ }^{1}$, Mark Fitzgerald ${ }^{1}$, Jin Tee ${ }^{1,2}$ \\ ${ }^{1}$ National Trauma Research Institute, Melbourne, VIC, Australia \\ ${ }^{2}$ Department of Neurosurgery, The Alfred Hospital, Melbourne, VIC, Australia \\ ${ }^{3}$ Department of Neurosurgery, St. Vincent's Hospital, Melbourne, VIC, Australia \\ ${ }^{4}$ Department of Orthopaedics, Erasmus MC, Rotterdam, Netherlands \\ ${ }^{5}$ Division of Orthopaedic Surgery, Northern Ontario School of Medicine, Sudbury, ON, Canada
}

The aim of this systematic review was to evaluate the surgical, radiological, and functional outcomes of posterior-only versus combined anterior-posterior approaches in patients with traumatic thoracolumbar burst fractures. The ideal approach (anterior-only, posterior-only, or combined anterior-posterior) for the surgical management of thoracolumbar burst fracture remains controversial, with each approach having its advantages and disadvantages. A systematic review following the Preferred Reporting Items for Systematic Reviews and Meta-Analyses guidelines was performed (registration no., CRD42018115120). The authors reviewed comparative studies evaluating posterior-only approach compared with combined anterior-posterior approaches with respect to clinical, surgical, radiographic, and functional outcome measures. Five retrospective cohort studies were included. Postoperative neurological deterioration was not reported in either group. Operative time, estimated blood loss, and postoperative length of stay were increased among patients in the combined anterior-posterior group in one study and equivalent between groups in another study. No significant difference was observed between the two approaches with regards to long-term postoperative Cobb angle (mean difference, -0.2; 95\% confidence interval, -5.2 to $4.8 ; p=0.936$ ). Moreover, no significant difference in functional patient outcomes was observed in the 36item Short-Form Health Survey, Visual Analog Scale, and return-to-work rates between the two groups. The available evidence does not indicate improved clinical, radiologic (including kyphotic deformity), and functional outcomes in the combined anterior-posterior and posterior-only approaches in the management of traumatic thoracolumbar burst fractures. Further studies are required to ascertain if a subset of patients will benefit from a combined anterior-posterior approach.

Keywords: Thoracic vertebrae; Lumbar vertebrae; Spinal fractures; Fracture fixation

Received Jun 22, 2019; Revised Jul 31, 2019; Accepted Aug 8, 2019

Corresponding author: Jin Tee

Department of Neurosurgery, Level 1, Old Baker Building, The Alfred Hospital, 55 Commercial Road, Melbourne, Victoria 3004, Australia

Tel: +61-3-90765704, Fax: +61-3-90763740, E-mail: jin.tee@ntrispine.com 


\section{Introduction}

Burst fractures involve the superior and/or inferior vertebral body endplate and extend into the posterior cortex. Fracture fragments may be retropulsed into the spinal canal, potentially causing canal stenosis and neurological compromise. Although significantly associated posterior osteoligamentous distraction and rotational or translational injury require surgical intervention [1], the management of thoracolumbar burst-only fractures remains unclear, particularly in neurologically intact patients or in those with isolated radiculopathy.

Among fractures requiring surgical intervention, a debate on which among the anterior, posterior, and combined anterior-posterior approaches provide the best outcomes remains. Historically, anterior-only approaches have been found to induce superior decompression due to its ability to directly remove fracture fragments. However, ongoing improvement on the stability of pedicle screw and the ability to place them quickly and safely has prompted some to use posterior fixation as a standalone procedure or as a supplementation of an anterior construct, particularly in fractures with associated kyphosis.

This systematic review aims to compare the surgical, radiological, and functional outcomes of a combined anterior-posterior approach with those of a posterior-only approach in the surgical fixation of traumatic thoracolumbar burst fractures in adult patients requiring surgical intervention.

\section{Materials and Methods}

This systematic review was conducted following the Preferred Reporting Items for Systematic Reviews and MetaAnalyses statement [2]. A study protocol was prospectively registered on the PROSPERO database (registration no., CRD42018115120).

\section{Eligibility criteria}

We included all studies comparing (prospectively or retrospectively) a combined anterior-posterior with a posterior-only approach for the management of a traumatic burst fracture located between T10 and L2, in which at least one of the following outcomes at 6-month followup was reported: neurological function (e.g., Frankel grading), kyphotic deformity (measured using the Cobb angle), postoperative complications, construct failure (any instrumentation fracture/breakage, implant loosening, or pullout), length of hospital stay, estimated blood loss, pre- and postoperative pain and functional scores (including Visual Analog Scale [VAS], Oswestry Disability Index [ODI], Roland-Morris Disability Questionnaire [RMDQ]), and ability to return to work.

We excluded studies that (1) focused on pathologic or osteoporotic, rather than traumatic, etiologies and (2) included nonburst morphologies (i.e., isolated endplate fractures, distraction injuries, translational injuries, rotational injuries, posterior osteoligamentous complex injuries, and AO type A1, A2, B, and C fractures). Studies assessing a heterogeneous sample of fracture types were eligible for inclusion provided disaggregated data were available for analysis of the burst fracture subgroup. Studies were not excluded based on the presence or absence of neurological compromise among the included sample.

\section{Information sources}

The MEDLINE/PubMed, Web of Science, EMBASE, Google Scholar, and Cochrane databases were searched from inception to December 30, 2018. In the MEDLINE/ PubMed database, Boolean operators were used to combine the following MeSH items in the MEDLINE/PubMed database: "Spinal Fractures," "Spinal Cord Injury," “Thoracic Vertebrae," "Lumbar Vertebrae," and "Fracture Fixation." This was supplemented by using a combination of the following "key words/topics" in the Web of Science, EMBASE, Google Scholar, and Cochrane databases: "Burst," "Burst Fracture," “Thoracolumbar," "A3," "A4," "Surgery," "Anterior," "Posterior," "Combined anteroposterior," and "Combined anterior-posterior."

\section{Study selection and data extraction}

Two authors (T.T. and J.T.) screened all articles independently and in duplicate for inclusion in this study, with contested citations referred to an independent author if necessary. Database searches were accompanied with manually searching the bibliographies of included studies to identify relevant articles.

Data from included studies were entered onto a preformatted data collection form by a single author (T.T.) and then independently verified by another author (J.T.). Extracted data included the journal and year of publication, 
number of authors, population demographics, operative details (description of procedure, type of decompression, type of instrumentation, duration of surgery, and estimated blood loss), and radiological (the Cobb angle at the final follow-up and change in the Cobb angle, i.e., the final Cobb angle at the follow-up and the preoperative Cobb angle), clinical (neurological function, mortality, and morbidity), and functional outcomes (e.g., VAS, ODI, and RMDQ). Surgical complication and construct failure rates were also extracted. We extracted the rationale for choosing a particular approach but did not control preoperative clinical/radiological variables for each study group.

\section{Assessment of reporting quality}

The methodological quality and risk of bias were assessed independently and in duplicate by two authors (T.T. and J.T.). Randomized studies received a score of "yes," "no," or "unclear" for each item described in the Cochrane assessment tool [3], whereas nonrandomized studies were evaluated using the Newcastle-Ottawa Quality Assessment Scale [4]. Discrepancies were resolved by discussion between the two authors (J.T. and T.T.).

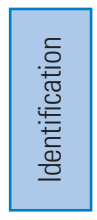

\section{Records identified through database searching $(n=4,015)$}

\section{Statistical analysis}

Due to the lack of controlled trials and high-quality retrospective studies, the reported results are mainly based on a qualitative synthesis of the available data. Where $>2$ studies reported quantitative data on the outcome variable of interest, the data were combined and summarized using mean differences (MDs) for continuous outcomes. Effect size and 95\% confidence interval (CI) are presented using forest plots. Meta-analysis was performed using OpenMetaAnalyst (Brown University, Providence, RI, USA). A $p$-value of $<0.05$ was considered statistically significant.

\section{Results}

\section{Literature search}

The systematic literature search yielded 4,015 initial studies whose titles and abstracts were screened. Of these, 40 articles were eligible for full-text review, out of which five studies were suitable for inclusion in this review [5-9]. Fig. 1 shows the initial literature search results and subsequent exclusion/inclusion of studies.
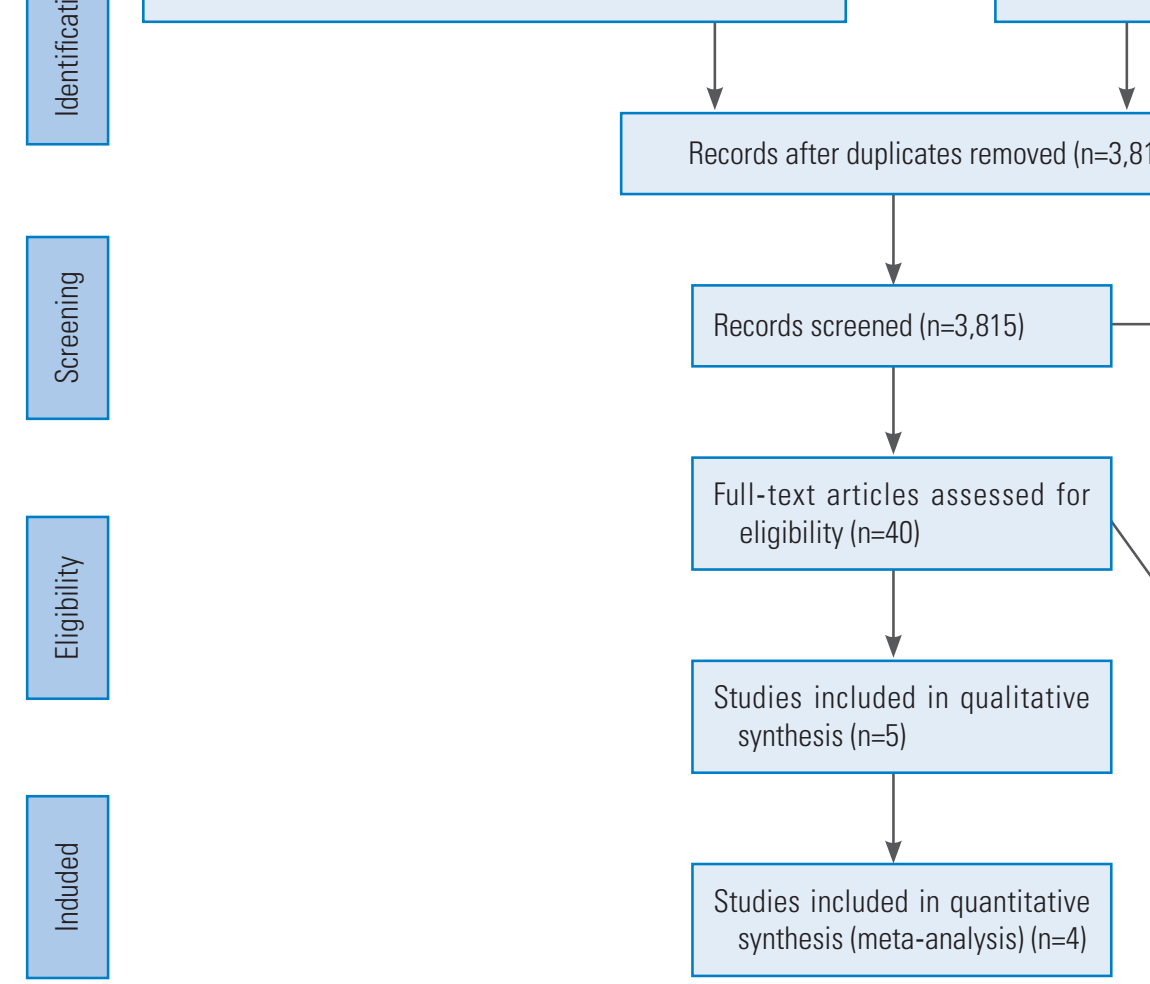

Additional records identified through other source $(n=0)$

Fig. 1. Preferred Reporting Items for Systematic Reviews and Meta-Analyses flow diagram. 


\section{Study characteristics}

All five included articles had a retrospective cohort design (level III evidence). The number of subjects in the included studies ranged from 20 to 46 (median, 35). The duration of follow-up ranged from 3 to 69 months (median, 27 months). One study investigated neurologically intact patients only [8], whereas two studies included neurologically intact and nonintact patients [5,7], and neurological status was not stated in two studies [6,9]. Table 1 summarizes patient demographics, fracture characteristics (including classification), and rationale of the approach of included studies.

\section{Qualitative analysis}

1) Description of the approach and operative technique Table 2 presents the combined anterior-posterior and posterior-only approaches with regards to method of fixation, fusion, and decompression. Generally, there was considerable variability in operative technique.
When stated, anterior approaches were performed with the patient in the right lateral decubitus position. Decompression from an anterior approach was frequently with the direct decompression of the visualized thecal sac $[5,7,9]$. Anterior column reconstruction was achieved with anterolateral screw-plate systems and/or vertebral body grafts, such as strut grafts or corpectomy cages.

In posterior approaches, decompression was obtained through a direct fashion $[7,9]$ or indirectly via ligamentotaxis/annulotaxis $[5,8]$. Posterior fixation was predominantly achieved with a pedicle screw and rod fixation.

\section{2) Neurological outcome}

Using Frankel grades, two studies that included neurologically intact and nonintact patients (Frankel A-E) reported pre- and postoperative neurological outcomes [5,7]. Postoperative neurological deterioration was not noted. In the study by Been and Bouma [5], except one patient in the posterior-only group, all neurologically compromised (Frankel A-D) patients in both surgical cohorts experienced an improvement of at least one Frankel

Table 1. Patient demographics and fracture classification

\begin{tabular}{|c|c|c|c|c|c|}
\hline \multirow[b]{2}{*}{ Variable } & \multicolumn{5}{|c|}{ Author (year) } \\
\hline & $\begin{array}{l}\text { Been and Bouma [5] } \\
\qquad(1999)\end{array}$ & $\begin{array}{c}\text { Briem et al. [6] } \\
\text { (2004) }\end{array}$ & $\begin{array}{c}\text { Danisa et al. [7] } \\
\text { (1995) }\end{array}$ & $\begin{array}{l}\text { Mayer et al. [8] } \\
\text { (2017) }\end{array}$ & $\begin{array}{c}\text { Schmid et al. [9] } \\
\text { (2012) }\end{array}$ \\
\hline Study design & Retrospective Cohort & Retrospective Cohort & Retrospective Cohort & Retrospective Cohort & Retrospective Cohort \\
\hline Total no. of patients & 46 & 20 & 33 & 36 & 35 \\
\hline No. of each group & AP, 27; post, 19 & AP, 10; post, 10 & AP, 6; post, 27 & AP, 14; post, 22 & AP, 14; post, 21 \\
\hline Age (yr) & AP, 26.8 $\pm 8.6 ;$ post, $33.7 \pm 13.1$ & $\begin{array}{l}\text { AP, } 63.00 \pm 49.6 \text {; post, } \\
59.0 \pm 48.2\end{array}$ & $\begin{array}{l}\text { AP, } 36.8 \text { (13-63); post, } 37.7 \\
\quad(19-75)\end{array}$ & $\begin{array}{l}\text { AP, } 34 \pm 10.6 ; \text { post } \\
\quad 42.0 \pm 14\end{array}$ & $\begin{array}{l}\text { AP, } 39.3 \pm 13.5 ; \text { post } \\
\quad 32.7 \pm 11.3\end{array}$ \\
\hline Gender (\% female) & AP, $44.4 \%$; post, $42.1 \%$ & AP, $60.0 \%$; post, $60.0 \%$ & AP, 33.3\%; post, $29.6 \%$ & $\begin{array}{l}\text { AP, } 28.6 \% \text {; post, } \\
50.0 \%\end{array}$ & $\begin{array}{l}\text { AP, } 23.81 \% \text {; post, } \\
\quad 42.86 \%\end{array}$ \\
\hline $\begin{array}{l}\text { Fracture classifica- } \\
\text { tion and typing (no. } \\
\text { of patients) }\end{array}$ & $\begin{array}{l}\text { Denis burst fractures only: } \\
\text { Denis type A (12/46); Denis } \\
\text { type B (20/46); Denis type C } \\
\text { (0/46); Denis type D (14/46); } \\
\text { Denis type E (0/46) }\end{array}$ & $\begin{array}{l}\text { Magerl type } 3 \text { frac- } \\
\text { tures only: Magerl } \\
\text { 3.1 (13/20); Magerl } \\
\text { 3.2 (5/20); Magerl } \\
3.3(2 / 20)\end{array}$ & $\begin{array}{l}\text { Denis burst fractures only: } \\
\text { Denis type } \mathrm{A}(21 / 33) \text {; } \\
\text { Denis type } \mathrm{B}(10 / 33) \text {; } \\
\text { Denis type } \mathrm{C}(2 / 33)\end{array}$ & $\begin{array}{l}\text { Magerl type } 3 \text { frac- } \\
\text { tures only: (36/36) }\end{array}$ & $\begin{array}{l}\text { Magerl type } 3 \text { frac- } \\
\text { tures only: (35/35) }\end{array}$ \\
\hline Neurological status & Intact and non-intact & Intact only & Intact and non-intact & Intact only & Intact only \\
\hline $\begin{array}{l}\text { Rationale for ap- } \\
\text { proach }\end{array}$ & $\begin{array}{l}\text { The choice for either type of } \\
\text { surgical approach was not } \\
\text { randomized, but was de- } \\
\text { cided by the surgeon based } \\
\text { on availability of instrumen- } \\
\text { tation and the presence of } \\
\text { severe other organ injuries. }\end{array}$ & Not reported & $\begin{array}{l}\text { The surgical procedure } \\
\text { performed were deter- } \\
\text { mined by each individual's } \\
\text { attending physician. }\end{array}$ & $\begin{array}{l}\text { The decision of } \\
\text { treatment was } \\
\text { according to the } \\
\text { attending sur- } \\
\text { geons' discretion. }\end{array}$ & $\begin{array}{l}\text { The patients were } \\
\text { treated according } \\
\text { to the surgeon's } \\
\text { preferences in a } \\
\text { single university- } \\
\text { based trauma } \\
\text { center. }\end{array}$ \\
\hline
\end{tabular}

Values are presented as number, mean \pm standard deviation, or mean (range).

$\mathrm{AP}$, anterior-posterior; post, posterior. 
grade during the follow-up. Danisa et al. [7] demonstrated similar results, with two of three neurologically compromised patients in the combined anterior-posterior cohort and eight of 11 in the posterior-only group, improving by one or more Frankel grades postoperatively.

3) Operative variables and length of hospital stay

Two studies reported the length of hospital stay, total duration of surgery, and estimated blood loss [7,9]. Danisa et al. [7] reported a postoperative length of stay of $13 \pm 4.5$ days for the posterior-only group and $22 \pm 7.0$ days for the combined anterior-posterior group. The duration of surgery was $219 \pm 61$ minutes (posterior-only group) compared with $569 \pm 121$ minutes (anterior-posterior group). Estimated blood loss was $1,103 \pm 793 \mathrm{~mL}$ (posterior-only group) compared with $2,541 \pm 1,439 \mathrm{~mL}$ (anterior-posterior group). Thus, the combined anterior-posterior approaches were associated with a significant increase in the total operative time, estimated blood loss, and postoperative length of hospital stay $(p<0.05)$.

Table 2. Summary of operative fixation, fusion, and decompression techniques

\begin{tabular}{|c|c|c|c|c|}
\hline Author (year) & $\begin{array}{l}\text { Positioning/ } \\
\text { approach }\end{array}$ & Decompression & Fixation & Supplemental fusion \\
\hline \multicolumn{5}{|l|}{$\begin{array}{l}\text { Combined anterior-posterior } \\
\text { approach }\end{array}$} \\
\hline Been and Bouma [5] (1999) & NR & $\begin{array}{l}\text { Direct canal decompres- } \\
\text { sion with subtotal } \\
\text { corpectomy }\end{array}$ & $\begin{array}{l}\text { Single rod slot-Zielke system; pedicle } \\
\text { screws and rods or Cottrel-Dubosset } \\
\text { compression rod system }\end{array}$ & $\begin{array}{l}\text { Anterior: ICBG anterior } \\
\text { strut }\end{array}$ \\
\hline Briem et al. [6] (2004) & NR & NR & $\begin{array}{l}\text { Pedicle screw and rod system (Depuy USS } \\
\text { Fracture System); anterolateral screw- } \\
\text { plate system (Aesculap MACS) }\end{array}$ & $\begin{array}{l}\text { Anterior: ICBG anterior } \\
\text { strut }\end{array}$ \\
\hline Danisa et al. [7] (1995) & $\begin{array}{l}\text { Right lateral de- } \\
\text { cubitus, prone }\end{array}$ & $\begin{array}{l}\text { Direct canal decompres- } \\
\text { sion with subtotal } \\
\text { corpectomy }\end{array}$ & $\begin{array}{l}\text { Kaneda device }(n=1) \text {; Harrington rods and } \\
\text { hooks }(n=1) \text {; Cotrel-Doubousset rods and } \\
\text { hooks }(n=1) \text {; Luque rings and sublaminar } \\
\text { wiring }(n=2) \text {; Texas Scottish Rite Hospital } \\
\text { rods and hooks }(n=2)\end{array}$ & $\begin{array}{l}\text { Anterior: fibular strut graft } \\
\text { or morselized rib graft; } \\
\text { posterior: ICBG or human } \\
\text { freeze-dried bone graft }\end{array}$ \\
\hline Mayer et al. [8] (2017) & $\begin{array}{l}\text { Right lateral de- } \\
\text { cubitus, prone }\end{array}$ & $\begin{array}{l}\text { Partial corpectomy but } \\
\text { dura not directly decom- } \\
\text { pressed }\end{array}$ & $\begin{array}{l}\text { Anterior: MACS plate/screw system; poste- } \\
\text { rior: Bisegmental pedicle screws; one } \\
\text { level up one down sparing fracture level }\end{array}$ & $\begin{array}{l}\text { Autologous bone graft or } \\
\text { distractable vertebral } \\
\text { body cage }\end{array}$ \\
\hline Schmid et al. [9] (2012) & $\begin{array}{c}\text { Right lateral } \\
\text { decubitus }\end{array}$ & $\begin{array}{l}\text { Thoracoscopic direct } \\
\text { decompression }\end{array}$ & $\begin{array}{l}\text { Pedicle screw (Depuy USS one level above } \\
\text { and one below fracture level) }\end{array}$ & $\begin{array}{l}\text { Anterior: tricortical strut } \\
\text { graft or titanium adjust- } \\
\text { able cage }\end{array}$ \\
\hline \multicolumn{5}{|l|}{ Posterior approach } \\
\hline Been and Bouma [5] (1999) & Prone & $\begin{array}{l}\text { Indirect decompression } \\
\text { only }\end{array}$ & AO internal fixator & NR \\
\hline Briem et al. [6] (2004) & Prone & NR & $\begin{array}{l}\text { Pedicle screw and rod system (Depuy USS } \\
\text { Fracture System) }\end{array}$ & NR \\
\hline Danisa et al. [7] (1995) & Prone & $\begin{array}{l}\text { Posterolateral transpe- } \\
\text { dicular approach ( } n=12 \text { ); } \\
\text { indirect decompression } \\
\text { with ligamentotaxis of } \\
\text { posterior longitudinal } \\
\text { ligament ( } n=15)\end{array}$ & $\begin{array}{l}\text { Steffee plates and pedicle screws }(n=16) \text {; } \\
\text { Cotrel-Doubousset rods with hook and } \\
\text { claw system }(n=4) \text {; Harrington distraction } \\
\text { rods and hooks }(n=4) \text {; Luque rings with } \\
\text { sublaminar wiring }(n=3)\end{array}$ & $\begin{array}{l}\text { IBGB or human freeze } \\
\text { dried bone }\end{array}$ \\
\hline Mayer et al. [8] (2017) & Prone & $\begin{array}{l}\text { Indirect decompression } \\
\text { only }\end{array}$ & Bisegmental pedicle screw fixation & NR \\
\hline Schmid et al. [9] (2012) & Prone & $\begin{array}{l}\text { Direct decompression via } \\
\text { TLIF approach }\end{array}$ & $\begin{array}{l}\text { Pedicle screws (USS Depuy one level above } \\
\text { and one below fracture level) }\end{array}$ & $\begin{array}{l}\text { Posterolateral fusion: } \\
\text { unilateral TLIF with } \\
\text { monocortical strut grafts } \\
\text { and ICBG }\end{array}$ \\
\hline
\end{tabular}

NR, not recorded; ICBG, iliac crest bone graft; MACS, modular anterior construct system; TLIF, transforaminal lumbar interbody fusion. 
Schmid et al. [9] found no statistical significant differences in the length of hospital stay $(11.8 \pm 5.2$ days versus $14.4 \pm 6.4$ days, $p=0.21$ ), operative duration (176 $\pm 72 \mathrm{~min}$ utes versus $213 \pm 41$ minutes, $p=0.10$ ), and estimated blood loss $(1,000 \pm 1,280 \mathrm{~mL}$ versus $1,100 \pm 790 \mathrm{~mL}, p>0.05)$ between the posterior-only and combined anterior-posterior groups.

4) Postoperative mortality and postoperative complications Postoperative mortality in four of the five included studies was not reported. Only three included studies recorded information on postoperative complications $[5,7,8]$. Been and Bouma [5] reported an overall complication rate of $14.8 \%$ (four of 27 patients, i.e., one infection, one instrumentation failure, and two misplaced pedicle screws) in the combined anterior-posterior group compared with 26.3\% (five of 19 patients, i.e., one infection and four instrumentation failures) in the posterior-only group. There was a $3.7 \%$ (one of 27 patients) and $21.1 \%$ (four of 19 patients) rate of construct failure (instrumentation breakage without clinical consequence) in the combined anteriorposterior and posterior-only groups, respectively.

Danisa et al. [7] reported an overall complication rate of $50.0 \%$ (three of six patients, i.e., one iatrogenic thoracic duct laceration intraoperatively, one apical pneumothorax, and one Kaneda device screw loosening) in the combined anterior-posterior group compared with 14.8\% (four of 27 patients, i.e., two infections, one pseudarthrosis, and one deep vein thrombosis) in the posterior-only group. The rate of construct failure in the combined anteriorposterior and posterior-only groups were 16.7\% (one of six patients) and $3.7 \%$ (one of 27 patients), respectively, without clinical sequelae. Mayer et al. [8] reported no instrumentation failure or breakage in all patients.

5) Relationship among the number of levels instrumented posteriorly, anterior column reconstruction, and con- struct failure rate

As mentioned, the method of fixation was heterogeneous between and within studies. In the combined anteriorposterior group, the number of levels instrumented during the posterior approach was specified only in Mayer et al. [8] and Schmid et al. [9] (both short segment, i.e., one level above and one level below the fractured vertebrae). The posterior groups in the two studies had short-segment fixation only. Mayer et al. [8] reported no instances of construct failure in both groups. However, this endpoint was not reported by Schmid et al. [9]. The number of segments instrumented posteriorly was not specified in the other three studies [5-7]. No studies specifically investigated the relationship among the number of levels instrumented posteriorly, anterior fixation, and postoperative construct failure. Thus, drawing any useful conclusions in this domain is not possible.

6) Postoperative Cobb angle at follow-up Four studies had sufficient data on long-term postoperative Cobb angle for meta-analysis [5,7-9] (Fig. 2). The collected postoperative Cobb angles for the combined anterior-posterior and for the posterior approaches were $8.5^{\circ}$ (range, $2.4^{\circ}-18.5^{\circ}$ ) and $8.5^{\circ}$ (range, $4.1^{\circ}-14.7^{\circ}$ ), respectively. No significant difference in postoperative Cobb angle at the final follow-up was observed between the combined anterior-posterior and posterior approaches (MD, 2.45; 95\% CI, -1.1 to $6.0 ; p=0.177$ ).

To evaluate the durability of the combined anteriorposterior and posterior approaches in correcting kyphotic deformity, available data regarding the change in the Cobb angle from the preoperative to the postoperative state from three studies were gathered and analyzed [7-9]. The change in the Cobb angle in the combined anterior-posterior approach was $7.5^{\circ}$ (range, $3.0^{\circ}-12.0^{\circ}$ ) compared with $4.2^{\circ}$ (range, $-3.6^{\circ}$ to $10.4^{\circ}$ ) in the posterior approach. No significant differences were observed on the change in the
Studies

Been and Bouma [5] (1999)

Danisa et al. [7] (1995)

Mayer et al. [8] (2017)

Schmid et al. [9] (2012)

Overall $\left(\mathrm{I}^{2}=23.71 \%, p=0.269\right)$
Mean difference (postoperative Cobb angle)

$0.800(-5.487$ to 7.087$)$

$-9.000(-22.842$ to 4.842$)$

$5.100(-0.184$ to 10.384$)$

$3.200(-1.432$ to 7.832$)$

$2.453(-1.107$ to 6.014$)$

Fig. 2. Postoperative Cobb angle deformity at follow-up.

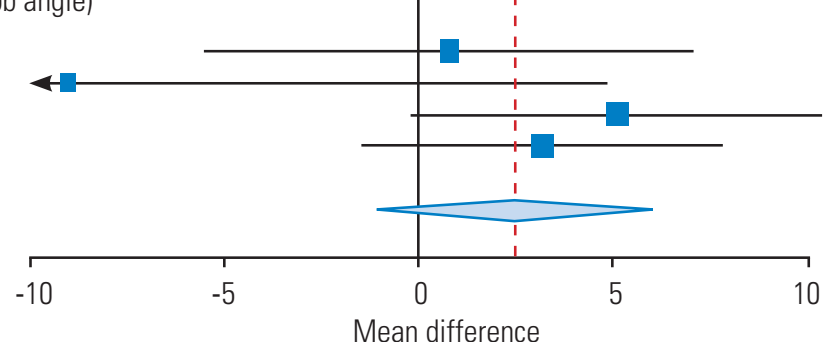


Cobb angle at the final postoperative follow-up between the combined anterior-posterior and posterior approaches (MD, -4.13 ; 95\% CI, -9.0 to 0.77 ; $p=0.098$ ) (Fig. 3).
7) Functional patient outcomes

Four studies reported functional patient outcomes using validated measures [6-9]. Utilizing the physical functioning, bodily pain, and mental health scales of the 36 -item
Studies

Danisa et al. [7] (1995)

Mayer et al. [8] (2017)

Schmid et al. [9] (2012)

Overall $\left(\mathrm{I}^{2}=0 \%, p=0.609\right)$
Estimate (95\% confidence interval)

-1.800 (-22.678 to 19.078)

$-6.600(-13.500$ to 0.300$)$

$-1.600(-8.971$ to 5.771$)$

$-4.129(-9.026$ to 0.768$)$

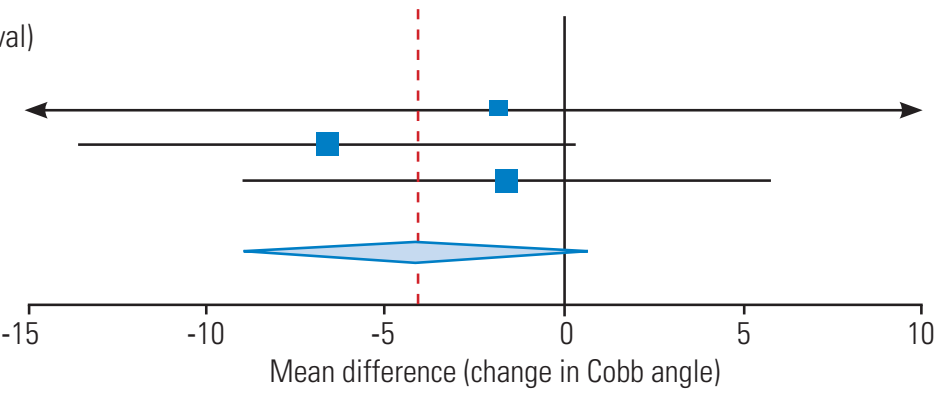

Fig. 3. Change in the Cobb angle at the final follow-up (compared with the preoperative state).

Table 3. Summary of patient functional outcomes

\section{Variable}

Briem et al. [6] (2004)

\begin{tabular}{|c|c|c|}
\hline SF-36 Physical Function Index & $77.5 \pm 3.89$ & $68.98 \pm 9.96$ \\
\hline SF-36 Body Pain Index & $60.7 \pm 8.68$ & $68.5 \pm 7.31$ \\
\hline SF-36 Mental Health Index & $76.6 \pm 4.13$ & $75.2 \pm 6.13$ \\
\hline \multicolumn{3}{|l|}{ Danisa et al. [7] (1995) } \\
\hline \multicolumn{3}{|l|}{ Denis Pain Index } \\
\hline P1-P2 (minimal to no pain) & P1-P2: 40 & P1-P2: 35 \\
\hline P3 (moderate pain) & P3: 20 & P3: 20 \\
\hline P4-5 (moderate to severe pain) & P4-5: 40 & P4-5: 45 \\
\hline \multicolumn{3}{|l|}{ Denis work } \\
\hline $\begin{array}{l}\text { W1-W2 (return to previous employment [heavy labor] or return to previous seden- } \\
\text { tary employment/heavy labor with restrictions) }\end{array}$ & W1-W2: 60 & W1-W2: 60 \\
\hline W3 (unable to return to previous employment but has returned to full-time work) & W3: 0 & W3: 0 \\
\hline W4-W5 (unable to return to full-time work or unable to return to any employment) & W4-5: 40 & W4-5: 39 \\
\hline Return to work (\%) & 60 & 60 \\
\hline \multicolumn{3}{|l|}{ Mayer et al. [8] (2017) } \\
\hline Oswestry Disability Index & $20 \pm 20$ & $16.3 \pm 17.1$ \\
\hline SF-36 Physical Component Score & $46.1 \pm 14.3$ & $49.3 \pm 9.4$ \\
\hline SF-36 Mental Component Score & $45.7 \pm 14.3$ & $51 \pm 14.1$ \\
\hline Visual Analogue Scale & $32.1 \pm 27.8$ & $17.1 \pm 18.2$ \\
\hline RMDO & $4.6 \pm 6.0$ & $3.3 \pm 4.2$ \\
\hline \multicolumn{3}{|l|}{ Schmid et al. [9] (2012) } \\
\hline Visual Analogue Scale (postoperative) & $68.4 \pm 17.4$ & $73 \pm 21.3$ \\
\hline RMD0 & $4.9 \pm 4.0$ & $4.4 \pm 4.4$ \\
\hline Return to work (\%) & 78.6 & 95.2 \\
\hline
\end{tabular}

Values are presented as mean \pm standard deviation or $\%$.

SF-36, 36-item Short-Form Health Survey; RMD0, Roland Morris Disability Questionnaire.

Anterior-posterior group Posterior group 
Short-Form Health Survey (SF-36) questionnaire, Briem et al. [6] reported no significant differences between the combined anterior-posterior and posterior-only groups. Mayer et al. [8] also reported no significant difference $(p>0.5)$ in the physical and mental component summaries of the SF-36 between the two groups. Mayer et al. [8] and Schmid et al. [9] both reported no significant differences on VAS scores specific for back pain between the combined anterior-posterior and posterior-only groups at postoperative follow-up.

Regarding return to work, Danisa et al. [7] reported a $60 \%$ rate of return to work for both groups, whereas Schmid et al. [9] reported $78.6 \%$ and $95.2 \%$ rates of return to at least some form of employment in the combined anterior-posterior and posterior-only groups, respectively, but this difference was not statistically significant $(p=0.18)$.

Table 3 summarizes the findings of the reported functional outcome measures of the relevant included articles.

\section{Quality assessment of individual studies}

By utilizing the Newcastle-Ottawa scale for observational cohort studies, three studies were found to be of good quality $[5,8,9]$, and two studies were of poor quality $[6,7]$ (Table 4). The study by Danisa et al. [7] was downgraded for the lack of comparison of demographic variables between groups at baseline and the study by Briem et al. [6] for the lack of specification of the adequacy and proportion of patients who were successfully followed up postoperatively.

\section{Discussion}

The management of traumatic thoracolumbar burst fractures remains controversial. Evidence-based management of these fractures has been inhibited by the lack of separation/classification of the different fracture types included in a single study. In an attempt to reduce this heterogeneity, the present systematic review has included burst-only fractures without distraction or translational injuries.

Relative indications for the surgical management of traumatic thoracolumbar burst fractures are (1) reversal/ stabilization of neurological deficit, (2) more than 50\% spinal canal compromise, and (3) deformity correction (e.g., kyphotic Cobb angle above $25^{\circ}$ ). Other potential surgical management markers include intractable back pain in a morphologically stable fracture and concomitant

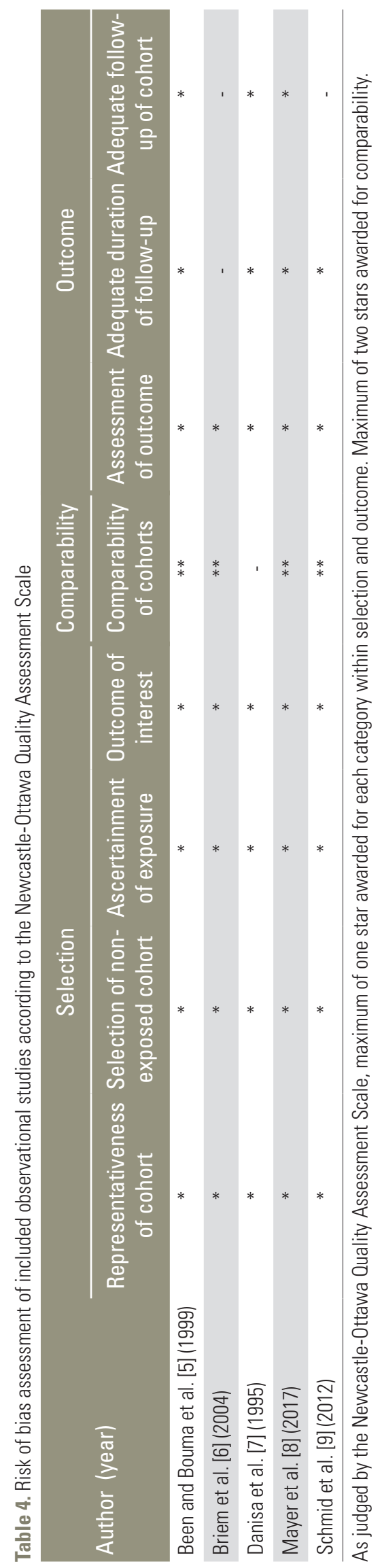


traumatic injuries (e.g., multiple rib fractures). The surgeon has to determine the best approach (i.e., anterior-only, posterior-only, or combined anterior-posterior), each with their relative advantages and disadvantages. A comparison between isolated anterior and posterior approaches has been the focus of previous systematic reviews and are outside the scope of this study $[10,11]$. These reviews have largely found no differences in terms of the neurological, functional, and quality-of-life outcomes between the anterior-only and the posterior-only approaches.

A combined anterior-posterior approach results in a patient receiving a longer total operative time, higher estimated blood loss, and longer hospital stay than a posterior-only approach. These findings are consistent with those reported by Danisa et al. [7] and Schmid et al. [9]. However, the combined anterior-posterior approach has the presumed advantages of allowing (1) a short-segment posterior fixation, which may be desirable in limiting disruption to lower lumbar motion segments [12]; (2) better kyphotic deformity correction [13]; and (3) direct fracture fragment removal for canal decompression.

Regarding short-versus long-segment fixation in thoracolumbar burst fractures, not enough data were available in this systematic review to conclude on the effect of anterior fixation and fusion on the number of levels required to be fixated posteriorly. The number of levels fixated posteriorly and the method of posterior instrumented fusion were heterogeneous between the studies in this review (Table 2). However, when considering short- versus longsegment posterior fixation (without anterior fixation) in thoracolumbar burst fractures, a recent meta-analysis by Aly [14] found no difference in the clinical, radiological (including kyphotic deformity), and functional outcomes. In this review, no evidence of a superior neurological outcome or less kyphotic deformity was found when comparing the combined anterior-posterior approach to the posterior-only approach. Furthermore, no statistically significant difference in terms of the change in the Cobb angle was observed at the final follow-up, indicating equivalence in the degree of deformity correction between the approaches. Nevertheless, anterior fixation in a combined anterior-posterior approach is likely to retain importance in selected cases with severe anterior column disruption [12].

With the development of minimally invasive surgery, the modern anterior approach applied to the thoracolumbar spine is considerably improved compared with the traditional open approach. In a retrospective cohort study comparing mini-open and traditional open anterior approaches to the thoracolumbar spine, Sulaiman et al. [15] reported a significantly reduced operative time, estimated blood loss, length of stay, and direct hospital costs in the mini-open group. The anterior approach may be a less major undertaking using contemporary techniques. Similarly, minimally invasive posterior techniques have been developed for thoracolumbar fractures. Compared with open approaches, percutaneous pedicle screw fixation has been found to result in reduced blood loss, shorter surgery, and similar VAS scores [16]. In recent meta-analyses, this approach had a shorter length of hospital stay, lower surgical site infection rate, and no differences in the postoperative Cobb angle $[17,18]$.

The main limitations of this systematic review lie in the characteristics and quality of the included articles. While limiting included articles to burst fractures only was helpful in reducing between-study heterogeneity, the inclusion of only isolated burst fractures reduced the number of articles meeting inclusion criteria. Included articles comprised patients who are neurologically intact and nonintact, and the subgroup analysis of the two groups were not performed. In practice, the clinical gestalt toward thoracolumbar burst fractures with neurological deficit is significantly different to that of a neurologically intact patient, as formalized in the Thoracolumbar Injury Classification System. Various specific techniques are used in each of the anterior and posterior approaches (Table 2), which accounts for at least some of the interstudy differences in the clinical outcomes of interest. Due to the small number of studies reporting each outcome of interest (see "Results" section), all except one outcome variable (i.e., postoperative Cobb angle) were unsuitable for metaanalysis. The authors decided not to apply meta-analyses to the outcome variables that were reported by two or less studies.

The ideal conceptual framework and study design to investigate different surgical approaches in thoracolumbar fractures is a well-designed randomized controlled trial (RCT). However, such an RCT is practically difficult to conduct, especially with respect to the study power and standardizing precise surgical procedures performed. An alternative to RCT is the utilization of large, prospective registries together with machine learning to investigate outcome differences between approaches. The application of artificial intelligence in spine surgery is a burgeoning 
field [19] and has the potential to predict preoperative variables that may benefit from a particular approach.

\section{Conclusions}

The current best available evidence does not present any difference in clinical, radiologic (including kyphotic deformity), and functional patient outcomes between the combined anterior-posterior approach and the posterioronly approach in the management of traumatic thoracolumbar burst fractures. The combined anterior-posterior approach shows longer operative duration, increased blood loss, and longer length of hospital stay. Further studies are required to determine if a specific subset of patients with thoracolumbar burst fractures will benefit from a combined anterior-posterior approach.

\section{Conflict of Interest}

No potential conflict of interest relevant to this article was reported.

\section{References}

1. Wood KB, Li W, Lebl DR, Ploumis A. Management of thoracolumbar spine fractures. Spine J 2014;14:14564.

2. Liberati A, Altman DG, Tetzlaff J, et al. The PRISMA statement for reporting systematic reviews and metaanalyses of studies that evaluate health care interventions: explanation and elaboration. J Clin Epidemiol 2009;62:e1-34.

3. Higgins JP, Green S; Cochrane Collaboration. Cochrane handbook for systematic reviews of interventions. Oxford: Cochrane Collaboration; 2011.

4. Stang A. Critical evaluation of the Newcastle-Ottawa scale for the assessment of the quality of nonrandomized studies in meta-analyses. Eur J Epidemiol 2010;25:603-5.

5. Been HD, Bouma GJ. Comparison of two types of surgery for thoraco-lumbar burst fractures: combined anterior and posterior stabilisation vs. posterior instrumentation only. Acta Neurochir (Wien) 1999;141:349-57.

6. Briem D, Lehmann W, Ruecker AH, Windolf J, Rueger JM, Linhart W. Factors influencing the quality of life after burst fractures of the thoracolumbar transition. Arch Orthop Trauma Surg 2004;124:4618.

7. Danisa OA, Shaffrey CI, Jane JA, et al. Surgical approaches for the correction of unstable thoracolumbar burst fractures: a retrospective analysis of treatment outcomes. J Neurosurg 1995;83:977-83.

8. Mayer M, Ortmaier R, Koller H, et al. Impact of sagittal balance on clinical outcomes in surgically treated T12 and L1 burst fractures: analysis of long-term outcomes after posterior-only and combined posteroanterior treatment. Biomed Res Int 2017;2017:1568258.

9. Schmid R, Lindtner RA, Lill M, Blauth M, Krappinger D, Kammerlander C. Combined posteroanterior fusion versus transforaminal lumbar interbody fusion (TLIF) in thoracolumbar burst fractures. Injury 2012;43:475-9.

10. Zhu Q, Shi F, Cai W, Bai J, Fan J, Yang H. Comparison of anterior versus posterior approach in the treatment of thoracolumbar fractures: a systematic review. Int Surg 2015;100:1124-33.

11. Xu GJ, Li ZJ, Ma JX, Zhang T, Fu X, Ma XL. Anterior versus posterior approach for treatment of thoracolumbar burst fractures: a meta-analysis. Eur Spine J 2013;22:2176-83.

12. McLain RF. The biomechanics of long versus short fixation for thoracolumbar spine fractures. Spine (Phila Pa 1976) 2006;31(11 Suppl):S70-9.

13. Bakhsheshian J, Dahdaleh NS, Fakurnejad S, Scheer JK, Smith ZA. Evidence-based management of traumatic thoracolumbar burst fractures: a systematic review of nonoperative management. Neurosurg Focus 2014;37:E1.

14. Aly TA. Short segment versus long segment pedicle screws fixation in management of thoracolumbar burst fractures: meta-analysis. Asian Spine J 2017;11:150-60.

15. Sulaiman OAR, Garces J, Mathkour M, et al. Miniopen thoracolumbar corpectomy: perioperative outcomes and hospital cost analysis compared with open corpectomy. World Neurosurg 2017;99:295-301.

16. Lee JK, Jang JW, Kim TW, Kim TS, Kim SH, Moon SJ. Percutaneous short-segment pedicle screw placement without fusion in the treatment of thoracolumbar burst fractures: is it effective?: comparative study with open short-segment pedicle screw fixation with posterolateral fusion. Acta Neurochir (Wien) 2013;155:2305-12. 
17. McAnany SJ, Overley SC, Kim JS, Baird EO, Qureshi SA, Anderson PA. Open versus minimally invasive fixation techniques for thoracolumbar trauma: a meta-analysis. Global Spine J 2016;6:186-94.

18. Phan K, Rao PJ, Mobbs RJ. Percutaneous versus open pedicle screw fixation for treatment of thoracolumbar fractures: systematic review and meta-analysis of comparative studies. Clin Neurol Neurosurg 2015;135:85-92.

19. Kim JS, Merrill RK, Arvind V, et al. Examining the ability of artificial neural networks machine learning models to accurately predict complications following posterior lumbar spine fusion. Spine (Phila Pa 1976) 2018;43:853-60. 